\title{
Czy młodzi ludzie są cyfrowymi tubylcami? Analiza wybranych wyników badań
}

DOI: 10.47050/65591777.146-159

Jacek Pyżalski

Tekst podejmuje kwestię zasadności stosowania określenia „cyfrowi tubylcy" w odniesieniu do młodych użytkowników internetu. Analizowane krytycznie są potencjalne kryteria takiego wyodrębnienia oraz wyniki badań odnoszące się do tych kryteriów, w tym ilościowych, dotyczących użytkowania internetu przez dzieci i młodzież w Polsce (EU Kids Online 2018). Tekst zamyka dyskusja dotycząca zasadności tzw. teorii generacji cyfrowych perse.

\section{Słowa kluczowe:}

cyfrowi tubylcy

generacje cyfrowe

internet

dzieci i młodzież 


\section{Are young people digital natives? Analysis of selected research results}

DOI: 10.47050/65591777.146-159

Jacek Pyżalski

The text raises the issue of the legitimacy of using the term 'digital natives' for young internet users. Critically analyzed are the potential criteria for such distinction and research results referring to such adopted criteria, including more recent quantitative research on Internet use by children and youth in Poland (EU Kids Online 2018). The text closes the discussion on the legitimacy of the so-called digital generation theories per se.

\section{Keywords:}

digital natives

digital generations

the internet

children and adolescents 


\section{Wprowadzenie}

Powszechne jest przekonanie o istotnej roli technologii informacyjno-komunikacyjnych w życiu młodych ludzi, a także o tym, że szczególnie wpływają one na kształtowanie młodzieży. Właśnie to zanurzenie w technologiach, które przenikają wszystkie dziedziny życia, sprawia, że młodzi ludzie mają być odmienni od poprzednich generacji.

Tego typu myślenie obecne jest w tak zwanych koncepcjach generacji cyfrowych, które polegają na nadaniu pewnemu pokoleniu młodych ludzi jakiejś nazwy, etykiety, i charakteryzowanie tego pokolenia głównie przez wskazanie specyficznego sposobu stosowania przez nie technologii lub funkcjonowania społecznego, które miałoby się z takim użytkowaniem wiązać. Zwykle w opisach obecne jest przekonanie o wiedzy eksperckiej młodych ludzi w zakresie używania technologii i ich znacznej przewagi w tym względzie nad pokoleniem dorosłych (głównie w ujęciu uczniów i nauczycieli).

Chyba najbardziej znaną i upowszechnioną koncepcją w dyskursie potocznym i naukowym (na przykład Krauze-Sikorska, Klichowski 2013) jest teoria Marca Prensky'ego (2001a; 2001b; 2009), określająca pokolenie młodych ludzi, którzy urodzili się w świecie internetu, mianem cyfrowych tubylców. Koncepcja ta została nakreślona w szeroko cytowanych tekstach (ponad 22 tysiące wskazań w Google Scholar), zawierających w tytule określenia digital natives (cyfrowi tubylcy) i digital immigrants (cyfrowi imigranci), a główną myślą tekstu było scharakteryzowanie pokolenia, które "urodziło się" z internetem, i pokolenia, w którym internet pojawił się dopiero na pewnym etapie życia (czyli musieli się go "uczyć"). Marc Prensky wskazuje, że zmiany generacyjne wywołane nowymi mediami są tak fundamentalne, że "nie ma drogi powrotu" (Prensky 2001, s. 1). Tym samym kwestionuje możliwości komunikacji międzypokoleniowej między takimi na wskroś różnymi generacjami. Uważa, że dzięki wpływowi technologii różnice generacyjne są głębsze i bardziej radykalne niż wcześniej, w czasach, w których - jego zdaniem - zmiana technologiczna nie była aż tak znaczna.

Marc Prensky (2001a; 2001b), przywołując dość wybiórczo dane z dziedziny neurobiologii, twierdzi, że korzystanie z nowych mediów od wczesnej młodości modyfikuje trwale anatomię mózgu i sposób, w jaki człowiek postrzega rzeczywistość i przetwarza informacje. Cyfrowi tubylcy preferują, zdaniem badacza, komunikację obrazową (w opozycji do tekstowej), bez trudu mogą czytać teksty oraz oglądać zdjęcia czy 
filmy w niewielkich okienkach na ekranie. Nie potrafią oni, w świetle tej charakterystyki, uczyć się linearnie oraz wykazują spore trudności z zapamiętywaniem dłuższych treści. Wolą materiały hipermedialne, które pozwalają im na przechodzenie (za pomocą linków) z pierwotnego dokumentu do wielu innych źródeł informacji (Prensky 2001a; 2001b; 2009).

To właśnie opisana koncepcja trafiła do tytułu niniejszego artykułu, ale tytuł ten należy odczytywać szerzej - jako symbol wszystkich rozważań podobnego typu. Istnieją przecież inne analizy oparte na podobnych założeniach, na przykład koncepcja „urodzonych cyfrowo” (Palfrey, Gasser 2008). Szeroką popularnością cieszy się także koncepcja „generacji sieci" (Tapscott 1998; 2009), w której wskazuje się, że młodzi ludzie myślą, pracują, bawią się, komunikują i robią zakupy w zupełnie inny sposób niż ich rodzice. Don Tapscott uważa, że generacja ta "wymusi" na szkole zmianę modelu kształcenia - z takiego, w którym w centrum znajduje się nauczyciel, na model sieciowy oparty na współpracy. Zdaniem tego autora, zmiany wynikają z faktu, że dla przedstawicieli generacji sieci podstawowym medium jest internet, a telewizja jest przez nich postrzegana jako przestarzały środek informacji. Ta mediocentryczność jest tutaj widoczna w samej nazwie generacji (n-gen, net generation).

Podobnie jest z koncepcją wyodrębnienia pokolenia milenialsów, które - choć jest szerszym pojęciem - w swoich charakterystykach zawiera wykorzystywanie technologii informacyjno-komunikacyjnych (Woodman 2015).

Warto zaznaczyć, że we wszystkich koncepcjach generacji cyfrowych technologie informacyjno-komunikacyjne są traktowane nie jako część życia młodej generacji (co jest oczywiste), ale jako centralny jego element i główny czynnik socjalizacyjny. Co interesujące - choć nie są to teorie zweryfikowane empirycznie, są one szeroko i bezkrytycznie przywoływane w pracach naukowych.

\section{Cyfrowi tubylcy - co to znaczy w wymiarze empirycznym?}

Jeśli chcielibyśmy potwierdzić lub zaprzeczyć istnieniu generacji cyfrowych, możemy empirycznie rozpoznawać różne aspekty funkcjonowania młodych ludzi w sieci oraz wymienić towarzyszące temu zjawiska i wymiary. W artykule przedyskutujemy kilka kluczowych aspektów, wskazując, do jakiego stopnia wskaźniki takie są relewantne jako wy- 
różniające generację cyfrową, i zilustrujemy tę dyskusję najnowszymi analizami, szczególnie reprezentatywnymi wynikami badania „EU Kids Online", zrealizowanego w 2018 r. na próbie polskich dzieci i młodzieży w wieku od dziewięciu do siedemnastu lat (Pyżalski, Zdrodowska, Tomczyk, Abramczuk 2019). Skupimy się na wykorzystaniu internetu, co jest powiązane z użytkowaniem większości innych technologii informacyjno-komunikacyjnych.

Rozważymy znaczenie następujących czynników:

$\rightarrow$ rozpowszechnienie i częstotliwość wykorzystania technologii informacyjno-komunikacyjnych,

$\rightarrow$ subiektywne znaczenie wykorzystania technologii i bycia online nadawane przez młodych ludzi,

$\rightarrow$ jakościowy aspekt i szeroki zakres wykorzystania technologii informacyjno-komunikacyjnych przez młode pokolenie.

\section{Rozpowszechnienie i czas wykorzystania technologii informacyjno-komunikacyjnych}

Panuje powszechne przekonanie, że wszyscy młodzi ludzie często i długo korzystają z internetu. Jest to przekonanie częściowo prawdziwe, częściowo zaś upraszczające, a nawet zakłamujące rzeczywistość.

Co prawda proste wskaźniki używania lub nawet codziennego użytkowania internetu wskazują, że obecnie prawie wszyscy młodzi ludzie korzystają z tego medium nie tylko w Polsce, ale także w innych krajach rozwiniętych (Pew Research Center 2018; Pyżalski 2012a; Tanaś i in. 2016). Najnowsze badania „EU Kids Online" także potwierdzają tę tendencję i dodatkowo pokazują, że coraz bardziej dominujący staje się internet mobilny - aż 82,5\% respondentów łączyła się z siecią codziennie lub kilka razy dziennie za pomocą smartfona lub telefonu komórkowego. Jednocześnie spada częstotliwość wykorzystania stacjonarnych form łączenia się z internetem - już ponad 18\% uczniów nigdy lub prawie nigdy nie używa laptopa lub komputera stacjonarnego do komunikacji online (Pyżalski, Zdrodowska, Tomczyk, Abramczuk 2019).

Kiedy jednak przyjrzymy się rozkładowi czasu przebywania online, okaże się wówczas, że w populacji polskich młodych ludzi występuje spore zróżnicowanie. Prawie jedna trzecia badanych używa internetu w dni powszednie najdłużej przez godzinę, a jedynie co dziesiąty przez sześć godzin i więcej. Podobne zróżnicowanie jest widoczne w korzystaniu z internetu w trakcie weekendów (ilustracja 1). 
Ilustracja 1. Czas spędzany w internecie w dni robocze i weekendowe

( $N=1249$ osób w wieku od dziewięciu do siedemnastu lat)

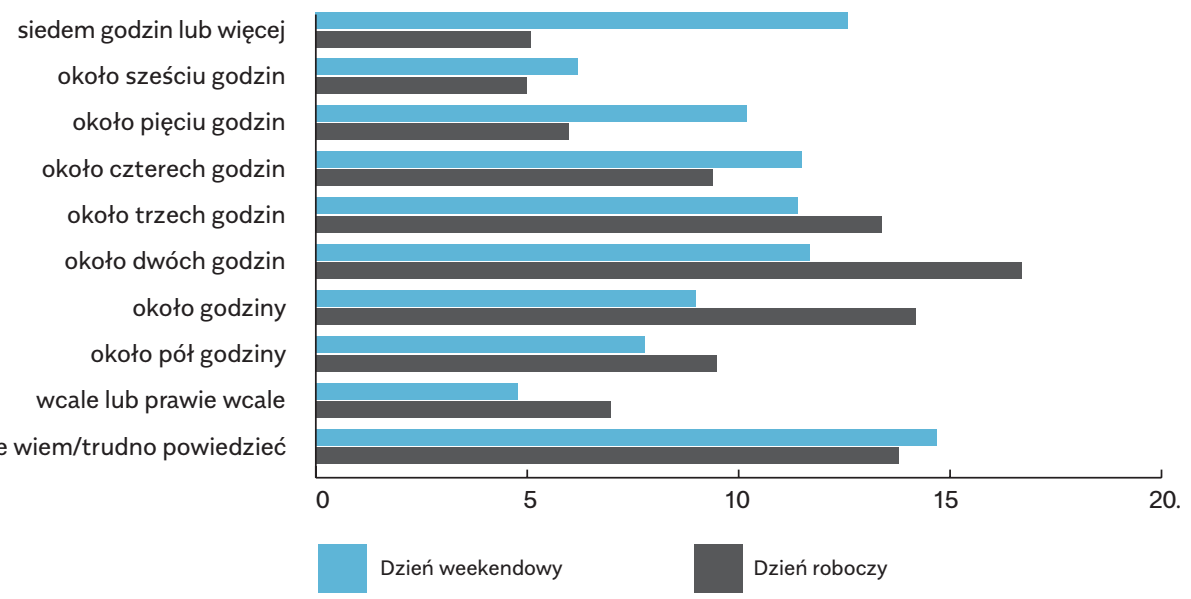

Źródło: Opracowanie własne na podstawie: J. Pyżalski, A. Zdrodowska, Ł. Tomczyk,

A. Abramczuk (2019).

Analizując te dane, warto przede wszystkim zwrócić uwagę, że chociaż w porównaniu z innymi grupami wiekowymi młodzi ludzie są tymi użytkownikami, którzy najczęściej korzystają z internetu, to wskaźniki w innych przedziałach wiekowych, jak wskazują analizy podłużne, także rosną (Batorski 2015). Wynika to między innymi z tego, że wzrasta wiek osób, które korzystały z internetu od urodzenia. Co za tym idzie - wiek pokoleń wychowanych bez sieci, które mogą służyć do porównań z "generacją cyfrową", jest także coraz wyższy.

Dodatkowo należy podkreślić ogromne zróżnicowanie czasu spędzanego online - populacja młodych ludzi nie jest, jak się zwykło uważać, szczególnie w codziennym oglądzie potocznym, jednorodna. Mamy w niej zresztą stosunkowo niewiele osób, które używają internetu bardzo krótko lub bardzo długo - jest to rozkład zbliżony do normalnego. Zróżnicowanie populacyjne użytkowania internetu zależy zresztą od wielu innych, bardziej ogólnych czynników, na przykład od statusu społeczno-ekonomicznego rodziny, w której wychowuje się młody człowiek (Pyżalski 2012a; 2012b; 2016; 2017).

Na koniec kwestia najważniejsza - dyskusyjne jest samo przyjmowanie wskaźnika użytkowania, a nawet częstego użytkowania internetu. 
Nie musi ono bowiem oznaczać (i często nie oznacza) głębszych zmian na poziomie psychologicznego i społecznego funkcjonowania młodych ludzi. Tym bardziej nie jest ono wystarczającym wskaźnikiem, kiedy uwzględnimy przywołany już fakt, że starsze grupy w populacji coraz mniej różnią się od młodszych pod tym względem.

\section{Subiektywne znaczenie wykorzystania technologii} i bycia online oraz samoocena kompetencji cyfrowych

Za wskaźnik przynależności do cyfrowej generacji można uznać szczególne znaczenie nadawane byciu online i komunikacji w sieci. W badaniach „EU Kids Online" respondenci odpowiadali na pytania między innymi o to, czy będąc online, łatwiej im być sobą, niż rozmawiając z ludźmi twarzą w twarz, o to, czy w internecie rozmawiają o sprawach osobistych, których nie ujawniają podczas spotkań bezpośrednich, oraz czy tematyka ich rozmów w internecie jest inna niż poza nim.

Tabela 1. Rozpowszechnienie wśród młodych ludzi przekonań dotyczących znaczenia internetu w ich życiu i w komunikacji ( $N=1249$ osób w wieku od dziewięciu do siedemnastu lat)

\begin{tabular}{l|c|c|c|c|c} 
& Nigdy & Czasem & Często & Zawsze & $\begin{array}{c}\text { Nie wiem/trudno } \\
\text { powiedzieć }\end{array}$ \\
\hline $\begin{array}{l}\text { Łatwiej mi być sobą w internecie niż } \\
\text { wtedy, gdy spotykam się z ludźmi } \\
\text { twarzą w twarz. }\end{array}$ & $42,3 \%$ & $27,8 \%$ & $8,8 \%$ & $7 \%$ & $14,2 \%$ \\
\hline $\begin{array}{l}\text { W internecie rozmawiam o sprawach } \\
\text { osobistych, których nie ujawniam } \\
\text { podczas spotkań twarzą w twarz. }\end{array}$ & $65,3 \%$ & $13,9 \%$ & $4,7 \%$ & $2,3 \%$ & $13,8 \%$ \\
\hline $\begin{array}{l}\text { W internecie rozmawiam o innych } \\
\text { rzeczach niż wtedy, gdy spotykam się } \\
\text { z ludźmi twarzą w twarz. }\end{array}$ & $39,1 \%$ & $29,1 \%$ & $11,7 \%$ & $5 \%$ & $15,1 \%$
\end{tabular}

Źródło: Opracowanie własne na podstawie: J. Pyżalski, A. Zdrodowska, Ł. Tomczyk,

A. Abramczuk (2019).

Analiza wskazanych przekonań nie pozwala stwierdzić, czy młodzi ludzie nadają sieci szczególne znaczenie lub postrzegają ją jako odrębne jakościowo środowisko komunikowania się z innymi ludźmi. Jedynie siedmiu na stu badanych stwierdza, że zawsze łatwiej im być sobą w internecie niż wtedy, gdy spotykają się z ludźmi twarzą w twarz, a 8,8\% 
deklaruje, że dzieje się tak często. Dobrze koresponduje to z wynikami dużych badań przeprowadzonych w Polsce osiem lat temu na grupie piętnastolatków. Jedynie co dziesiąty badany stwierdził, że wśród jego zainteresowań internet jest na pierwszym miejscu (Pyżalski 2012a).

Równie rzadko wybór komunikacji zapośredniczonej (przez internet) przekłada się, zdaniem badanych, na to, że są skłonni do rozmowy na bardziej osobiste tematy (około $7 \%$ odpowiedzi "często" i "zawsze") i że tematyka ich rozmów jest inna online w porównaniu z rozmowami offline (łącznie "często" i „zawsze" stanowi mniej niż $17 \%$ odpowiedzi).

Taki rozkład odpowiedzi oznacza, że internet ma duże znaczenie (przy takim sposobie jego wskaźnikowania) dla mniejszej części populacji młodych ludzi. Dodatkowo zwracają uwagę wysokie odsetki tych użytkowników, którym internet nie pomaga w byciu sobą i którzy nigdy nie komunikują się w sieci w inny sposób niż poza nią (dotyczy to także spraw osobistych).

Trudno zatem uznać, że internet jest traktowany przez ogół młodych ludzi jako szczególne środowisko komunikacyjne czy społeczne. Jest on raczej obszarem funkcjonowania, w którym przejawiają się różne jego aspekty determinowane przez inne - pozainternetowe - czynniki.

Innym ważnym aspektem jest samoocena umiejętności cyfrowych. Respondenci badania "EU Kids Online" (osoby w wieku od jedenastu do siedemnastu lat) okazali się pod tym względem bardzo autokrytyczni - wbrew powszechnemu przekonaniu, że młodzi ludzie wiele potrafią, oni sami wyrażają dużo niższą ocenę własnych umiejętności (Pyżalski, Zdrodowska, Tomczyk, Abramczuk 2019). 
Tabela 2. Ocena własnych umiejętności internetowych przez

młodych ludzi - odsetki oceniających najwyżej ( $N=985$, starsza

młodzież w wieku od jedenastu do siedemnastu lat)

OCENA WŁASNYCH UMIEJĘTNOŚCI INTERNETOWYCH

CAŁA PRÓBA MŁODZIEŻY

W WIEKU OD JEDENASTU

DO SIEDEMNASTU LAT

Wiem, jak instalować aplikacje na urządzeniu mobilnym (na przykład telefonie lub tablecie).

$74,8 \%$

Wiem, jak usunąć osoby z mojej listy kontaktów.

$74,6 \%$

Wiem, jakie informacje powinno się udostępniać, a jakich nie powinno się umiesz-

czać w internecie.

$66,2 \%$

Wiem, jak zapisać zdjęcie znalezione w internecie.

$62,9 \%$

Wiem, jak zmienić moje ustawienia prywatności (na przykład na portalu społecznościowym).

$59,9 \%$

Wiem, jak robić zakupy za pośrednictwem aplikacji mobilnych.

$50,7 \%$

Wiem, jak sprawdzać koszty korzystania z aplikacji mobilnych.

$49,2 \%$

Wiem, jak tworzyć i publikować w internecie filmy albo muzykę.

$39,0 \%$

Łatwo mi wybrać najlepsze słowa kluczowe, żeby wyszukać coś w internecie.

$37,6 \%$

Łatwo mi sprawdzić, czy informacja znaleziona przeze mnie w internecie

jest prawdziwa.

$31,9 \%$

Wiem, jak edytować lub zmieniać treści w internecie, które inni stworzyli

i zamieścili online.

$24,0 \%$

Źródło: Opracowanie własne na podstawie: J. Pyżalski, A. Zdrodowska, Ł. Tomczyk,

A. Abramczuk (2019). 
Analizując dane w zakresie samooceny umiejętności korzystania z internetu (tabela 2), można się przekonać, że nawet stosunkowo proste umiejętności, które, notabene, często są ćwiczone w ramach programu nauczania w szkole, nie są - zdaniem młodych ludzi - dobrze przez nich opanowane. Ta niska ocena dotyczy przede wszystkim umiejętności związanych z bezpieczeństwem (sześciu na dziesięciu badanych uważa, że opanowało je bardzo dobrze) czy poszukiwaniem i oceną wiarygodności informacji znalezionych online (wysoko w zakresie tych umiejętności ocenia siebie tylko około jedna trzecia badanych). Trzeba wziąć jeszcze pod uwagę fakt, że w badaniach, w których rzeczywisty poziom umiejętności nie jest obiektywnie weryfikowany, wartości wskaźników są zawyżone wobec rzeczywistych umiejętności.

Po raz kolejny zatem najnowsze badania potwierdziły, widoczne już wcześniej obserwacje (por. Pyżalski 2012a; 2012b), że młodzi ludzie stosunkowo nisko oceniają własne kompetencje cyfrowe, a także są bardzo zróżnicowani w zakresie opanowania umiejętności, których wysokie wskaźniki przypisuje się często błędnie całej populacji. Trudno tu zatem mówić o pozytywnej weryfikacji charakterystyki zawartej w większości koncepcji generacji cyfrowej, z której wynika wysokie zaawansowanie w wykorzystaniu technologii informacyjno-komunikacyjnych. Niewątpliwie jednak, z punktu widzenia weryfikacji empirycznej koncepcji generacji cyfrowych, wskaźnik ten należy uznać za istotny i warty zastosowania.

\section{Jakościowy aspekt i szeroki zakres wykorzystania technologii informacyjno- -komunikacyjnych przez młode pokolenie}

Ostatnim, ale bardzo ważnym wskaźnikiem przynależności młodych ludzi do generacji cyfrowej, jest analiza ich rzeczywistych aktywności online. Idzie zatem nie tyle o sam fakt używania internetu i czas tego użytkowania, ile o jakość i zakres podejmowanych aktywności (tabela 3). 
Tabela 3. Aktywność młodych ludzi w internecie w ciągu miesiąca poprzedzającego badanie ( $N=1249$, osoby w wieku od dziewięciu do siedemnastu lat, dane w \%)

\begin{tabular}{|c|c|c|c|c|c|c|c|}
\hline & NIGDY & $\begin{array}{l}\text { PRAWIE } \\
\text { NIGDY }\end{array}$ & $\begin{array}{l}\text { PRZYNAJMNIEJ } \\
\text { RAZ } \\
\text { W TYGODNIU }\end{array}$ & $\begin{array}{l}\text { CODZIENNIE } \\
\text { LUB PRAWIE } \\
\text { CODZIENNIE }\end{array}$ & $\begin{array}{c}\text { KILKA } \\
\text { RAZY } \\
\text { DZIENNIE }\end{array}$ & $\begin{array}{l}\text { PRAWIE } \\
\text { CAŁY } \\
\text { CZAS }\end{array}$ & $\begin{array}{l}\text { NIE WIEM LUB } \\
\text { WOLĘ NIE } \\
\text { ODPOWIADAĆ }\end{array}$ \\
\hline $\begin{array}{l}\text { Włączyłem/włączyłam się } \\
\text { w kampanię (protest) albo podpi- } \\
\text { sałem/podpisałam petycję online. }\end{array}$ & 79,5 & 9,8 & 3,0 & 0,9 & 0,5 & 0,3 & 5,9 \\
\hline $\begin{array}{l}\text { Dyskutowałem/dyskutowałam } \\
\text { online w innymi osobami na te- } \\
\text { maty społeczne lub polityczne }\end{array}$ & 72,4 & 11,4 & 6,5 & 2,5 & 1,5 & 0,5 & 5,3 \\
\hline $\begin{array}{l}\text { Przygotowałem/przygotowałam } \\
\text { własne wideo lub własną muzykę } \\
\text { i udostępniłem/udostępniłam te } \\
\text { materiały online. }\end{array}$ & 68,3 & 16,3 & 6,2 & 2,2 & 1,1 & 0,6 & 5,3 \\
\hline $\begin{array}{l}\text { Używałem/używałam internetu do } \\
\text { rozmowy z ludźmi z innych krajów. }\end{array}$ & 52,9 & 19,2 & 10,8 & 6,8 & 3,0 & 2,1 & 5,1 \\
\hline $\begin{array}{l}\text { Uczestniczyłem/uczestniczyłam } \\
\text { w grupie online, w której ludzie } \\
\text { dzielą się swoimi zainteresowa- } \\
\text { niami/hobby. }\end{array}$ & 48,7 & 16,3 & 12,2 & 9,8 & 4,5 & 3,2 & 5,4 \\
\hline $\begin{array}{l}\text { Szukałem/szukałam informacji } \\
\text { na temat zdrowia, potrzebnych } \\
\text { mnie lub komuś, kogo znam. }\end{array}$ & 45,3 & 26,5 & 13,1 & 4,6 & 1,9 & 1,1 & 7,4 \\
\hline $\begin{array}{l}\text { Odwiedzałem/odwiedzałam } \\
\text { portal społecznościowy. }\end{array}$ & 25,3 & 7,8 & 12,2 & 21,6 & 17,5 & 10,2 & 5,4 \\
\hline $\begin{array}{l}\text { Używałem/używałam internetu } \\
\text { do nauki w szkole. }\end{array}$ & 25,2 & 20,9 & 30,4 & 11,1 & 3,6 & 2,0 & 6,7 \\
\hline $\begin{array}{l}\text { Szukałem/szukałam w internecie } \\
\text { informacji z kraju i ze świata. }\end{array}$ & 24,7 & 26,3 & 27,1 & 9,4 & 3,4 & 1,7 & 7,4 \\
\hline $\begin{array}{l}\text { Grałem/grałam w gry online (sam/ } \\
\text { sama). }\end{array}$ & 18,2 & 18,7 & 24,7 & 18,3 & 9,6 & 5,1 & 5,4 \\
\hline $\begin{array}{l}\text { Szukałem/szukałam czegoś do } \\
\text { kupienia lub informacji, ile coś } \\
\text { kosztuje. }\end{array}$ & 15,3 & 21,9 & 33,4 & 13,5 & 5,2 & 4,0 & 6,8 \\
\hline $\begin{array}{l}\text { Szukałem/szukałam informacji do- } \\
\text { tyczących możliwości pracy/nauki. }\end{array}$ & 11,9 & 22,2 & 35,1 & 13,6 & 4,0 & 3,5 & 9,7 \\
\hline $\begin{array}{l}\text { Komunikowałem/komunikowa- } \\
\text { łam się z rodziną lub przyjaciółmi. }\end{array}$ & 8,3 & 8,7 & 16,9 & 28,9 & 18,5 & 13,0 & 5,7 \\
\hline $\begin{array}{l}\text { Słuchałem/słuchałam muzyki } \\
\text { online. }\end{array}$ & 8,1 & 8,8 & 15,9 & 27,9 & 19,1 & 14,5 & 5,8 \\
\hline Oglądałem/oglądałam filmiki. & 4,0 & 6,3 & 18,6 & 33,9 & 21,6 & 9,9 & 5,7 \\
\hline
\end{tabular}

Źródło: Opracowanie własne na podstawie: J. Pyżalski, A. Zdrodowska, Ł. Tomczyk,

A. Abramczuk (2019). 
Okazuje się, że najczęściej podejmowanymi aktywnościami są: oglądanie filmików, słuchanie muzyki, codzienne komunikowanie się z rodziną i przyjaciółmi. Są to działania (szczególnie pierwsze z wymienionych), w których użytkownik jest bierny i które mogłyby być z powodzeniem realizowane za pomocą telewizji i radia. Trudno byłoby być krytycznym wobec tych wyników, gdyby inne, bardziej społeczne aktywności online były realizowane równie często.

Warto zauważyć, że w badaniu wykazano wiele różnic wewnątrz badanej populacji, związanych z podejmowanymi aktywnościami, a dotyczących płci i wieku. Jak wskazują inne badania, aktywności w internecie są również powiązane ze statusem społeczno-ekonomicznym, co wiąże się ze zjawiskiem nierówności cyfrowych. Oznacza to, że obecnie nierówności takie nie wynikają z dostępu do sprzętu czy łącza internetowego, ale właśnie z tego, kto i do czego potrafi internetu używać (van Dijk 2012).

Biorąc pod uwagę dotychczasowe rozważania, trudno zatem uznać, że technologie przenikają wszystkie sfery funkcjonowania młodych ludzi, ponieważ wielu z nich nie podejmuje w sieci wartościowych i twórczych działań lub podejmuje je jedynie w niewielkim stopniu. Oczywiście przyczyną takiego stanu rzeczy mogą być inne, bardziej ogólne czynniki - na przykład jeśli ktoś nie angażuje się w żadne akcje społeczne, to najczęściej nie robi tego również za pomocą mediów cyfrowych, a jeśli nie interesuje się informacjami dziennikarskimi, to nie szuka ich również w internecie. Taka interpretacja jednak jeszcze bardziej uwypukla fakt, że tradycyjne czynniki socjalizacyjne, niezwiązane z mediami cyfrowymi, wciąż mają duże znaczenie, także w zakresie wykorzystania internetu. Nadawanie zatem sieci kluczowego znaczenia w socjalizacji młodych ludzi, bez holistycznego, wieloczynnikowego spojrzenia, jest bezzasadne.

\section{Koncepcje generacji cyfrowych - podejście krytyczne}

Przywołane wcześniej wyniki badań chciałbym wykorzystać do krytyki samych założeń koncepcji generacji cyfrowych. Nie jest to pierwsza negatywna naukowa ocena tego zjawiska - koncepcje takie (szczególnie autorstwa Marca Prensky'ego) były już wcześniej opisywane (Bennett, Maton, Kervin 2008; Boyd 2010; Helsper, Eynon 2010; Pyżalski 2012b). 
Naukowcy podnosili głównie następujące argumenty:

$\rightarrow$ Koncepcje te często opierają się na anegdotycznych obserwacjach funkcjonowania młodych ludzi i dotyczą przeważnie jednostek. Populacyjne badania naukowe nie potwierdzają większości charakterystyk podkreślanych w koncepcjach generacji cyfrowych (przynajmniej w odniesieniu do całej lub większości populacji). W badaniach przedstawionych $w$ niniejszym artykule prawidłowość ta się potwierdziła. Obecnie brakuje wystarczających dowodów empirycznych potwierdzających założenia koncepcji dotyczących generacji cyfrowych (por. Pyżalski 2012b).

$\rightarrow$ Autorzy tego rodzaju idei przypisują internetowi zbyt dużą wagę w życiu młodych ludzi. Lokują go błędnie w centrum życia młodzieży, pomijając inne czynniki wpływające na kształtowanie ich rozwoju osobistego i społecznego. Jak wskazuje Neil Selwyn, „takie deterministyczne dyskursy ukrywają kluczowe czynniki wartości i relacje, które kryją się za coraz szerszym zastosowaniem technologii w społeczeństwie" (Selwyn 2003, s. 368).

$\rightarrow$ Twórcy teorii (zgodnie z omówionym wcześniej błędem prezentyzmu) pomijają informacje o tym, że niektóre właściwości przypisywane obecnej generacji były mocno zaznaczone także wcześniej (w czasach przed internetem). Można tu wymienić choćby multitasking, który w jakiejś części dotyczył także poprzednich pokoleń.

$\rightarrow$ Teorie te nie uwzględniają ewolucji internetu oraz tego, że obecnie w większości krajów zarówno dorośli, jak i młodzi ludzie to aktywni użytkownicy tego medium.

$\rightarrow$ Teorie te pomijają zróżnicowanie w populacji młodych użytkowników internetu, przypisując całej populacji wysokie kompetencje cyfrowe, które dotyczą w rzeczywistości jedynie mniejszej grupy młodych ludzi.

Bezkrytyczne przyjmowanie koncepcji generacji cyfrowych jest ślepą uliczką dla pedagogów - i to zarówno tych, którzy są badaczami, jak i tych, którzy realizują się w sferze praktycznej (Boyd 2014). Wynikająca z nich fałszywa diagnoza może prowadzić do nieprzemyślanych i bezwartościowych działań dydaktycznych i wychowawczych, projektujemy je bowiem dla populacji, której obraz jest uproszczony, karykaturalny i fałszywie jednorodny (choć w rzeczywistości jest ona bardzo zróżnicowana wewnętrznie). 
Obserwując obecny dyskurs dotyczący młodych ludzi, powtórzyłbym apel Susan Herring (2008), który przywoływałem wcześniej (Pyżalski 2012b). Autorka ta, kwestionująca radykalne koncepcje międzygeneracyjnego podziału cyfrowego, wskazuje konieczność zmiany paradygmatu, tak by uwaga została przeniesiona $z$ technologii na potrzeby młodych ludzi. Powinny być one traktowane jako punkt wyjścia, a analizy mają dotyczyć tego, jak są one zaspokajane w czasach mediów cyfrowych. Postulat taki jest wartościowy także z perspektywy aksjologicznej i z pewnością daje on większe szanse na budowanie fundamentu teorii pedagogicznych, które mogą stanowić podstawę działań praktycznych. Jak wskazuje Neil Selwyn (2009, s. 366), istnieje "paląca potrzeba, aby rozwijać i upowszechniać realistyczne rozumienie relacji młodych ludzi z technologią [...] jeżeli chcemy odegrać ważną i użyteczną rolę w wspieraniu obecnej generacji młodych". 